\title{
DOCUMENTOS PÚBLICOS CON FUERZA EJECUTIVA Y TRANSACCIONES JUDICIALES EN EL MARCO DE LOS REGLAMENTOS GEMELOS ${ }^{1 *}$
}

IVANA KUNDA

Catedrática de Derecho internacional privado en la Facultad de Derecho de la Universidad de Rijeka

E-mail: ikunda@pravri.hr

MARTINA TIČIĆ

Ayudante predoctoral en la Facultad de Derecho de la Universidad de Rijeka

E-mail: mticic@pravri.hr

\begin{abstract}
RESUMEN: Este capítulo analiza los requisitos y procedimientos para la libre circulación de los documentos públicos y las transacciones judiciales entre los Estados miembros. Primero se centra en las nociones básicas, que incluyen los "documentos públicos", la "transacciones judiciales, la "autenticidad" y los mecanismos, que son la "aceptación" y el "otorgamiento de la ejecución". Además, comenta el número de normas procesales unificadas que son aplicables en los procedimientos relacionados con la extensión de los efectos.
\end{abstract}

Palabras clave: transacciones judiciales, autenticidad, aceptación, otorgamiento de la ejecución.

ABSTRACT: This paper deals with requirements and procedures for free circulation of authentic instruments and court settlements among Member States. First it focuses on the basic notions, including 'authentic instruments', 'court settlement', 'authenticity', and mechanisms, being the 'acceptance' and the 'declaration of enforceability'. It further contains comments on the number of unified procedural rules which are applicable in the proceedings relating to extension of effects.

Keywords: authentic instruments, court settlement, authenticity, acceptance, declaration of enforceability.

1 * Traducido por Ana María Pérez Vallejo, Profesora Titular de Derecho civil y Nuria Martínez Sánchez, Doctora en el departamento de Derecho civil de la Universidad de Almería. 
SUMARIO: I. INTRODUCCIÓN. II. LAS NOCIONES DE "DOCUMENTO PÚBLICO” Y DE "TRANSACCIÓN JUdICIAL". 2.1. "Documento público" con fuerza ejecutiva 2.1.1. Participación de la autoridad pública 2.1.2. Papel de la autoridad pública 2.1.3. En papel o en formato electrónico. 2.2. Características del "instrumento auténtico". 2.2.1. Elementos relacionados con la forma y el contenido. 2.2.2. Distinción de las "decisiones". 2.2.3. Distinción de los "documentos públicos” según el reglamento 2016/1191. 2.3. Definición de "transacción judicial”. 2.3.1. Acuerdo entre las partes 2.3.2. Implicación del tribunal. 2.3.3. Distinción de las "consent judgments" (sentencias basadas en acuerdo de las partes). 2.4. Ampliación de los efectos de los documentos públicos con fuerza ejecutiva y de las transacciones judiciales. 2.5. "Aceptación" de los documentos públicos con fuerza ejecutiva. 2.5.1. La noción de "aceptación". 2.5.2. Extensión de los efectos probatorios. 2.5.3. Formulario normalizado opcional. 2.5.4. Retos y obstáculos para la "aceptación". 2.5.5. El orden público como motive de denegación de la "aceptación". 2.5.6. Incompatibilidad con otros documentos públicos, acuerdos o decisiones judiciales 2.6. "Declaración de ejecutividad" de los documentos públicos con fuerza ejecutiva y de las transacciones judiciales. 2.6.1. Ejecución en el Estado miembro de origen. 2.6.2. Procedimiento de declaración de la fuerza ejecutiva en el Estado miembro de ejecución. 2.6.3. Recursos legales contra el auto de ejecución. III. OBSERVACIONES FINALES.

\section{INTRODUCCIÓN}

Los documentos públicos con fuerza ejecutiva tienen especial importancia práctica para los asuntos patrimoniales de la familia, incluidos los asuntos matrimoniales y los relacionados con los efectos patrimoniales de las parejas registradas. ${ }^{2}$ Como medio de asegurar la justicia preventiva, permiten el control legal preventivo a través de la autenticación de documentos para las transacciones legales de alto interés económico o personal para el interés del público o de las partes individuales. ${ }^{3}$ Junto con la transacción judicial, los documentos públicos con fuerza ejecutiva también constituyen una categoría importante de títulos ejecutivos, al menos en la mayoría de las jurisdicciones de los Estados miembros. ${ }^{4}$ Los acuerdos judiciales suelen considerarse títulos ejecutivos siempre que estén registrados o atestiguados por un tribunal. Por otro lado, los documentos públicos se suelen considerar títulos ejecutivos en las jurisdicciones de Civil Law, y no tanto en las de Common Law o escandinavo. ${ }^{5}$ Incluso en los Estados en los que tanto los documentos públicos como las transacciones judiciales presentan un título ejecutivo, existen varias diferencias entre las autoridades emisoras, los propios instrumentos o los procedimientos para su ejecución.

2 Propuesta de Reglamento del Consejo relativo a la competencia, la ley aplicable, el reconocimiento y la ejecución de las resoluciones en materia de regímenes matrimoniales, COM/2011/0126 final - CNS 2011/0059, p. 10; Propuesta de Reglamento del Consejo relativo a la competencia, la ley aplicable, el reconocimiento y la ejecución de las resoluciones sobre los efectos patrimoniales de las parejas de hecho, COM/2011/0127 final - CNS 2011/0060, p. 9. Véase también la Propuesta de Reglamento del Parlamento Europeo y del Consejo relativo a la competencia, la ley aplicable, el reconocimiento y la ejecución de las resoluciones y los actos auténticos en materia de sucesiones y a la creación de un certificado sucesorio europeo, COM/2009/0154 final - COD 2009/0157, p. 7.

3 Council of the Notariats of the European Union, Comparative Study on Authentic Instruments National Provisions of Private Law, Circulation, Mutual Recognition and Enforcement, Possible Legislative Initiative by the European Union - United Kingdom, France, Germany, Poland, Sweden, European Parliament, Brussels 2008, <https://www.europarl. europa.eu/RegData/etudes/STUD/2008/408329/IPOL-JURI_ET(2008)408329 EN.pdf $>$ accessed 10.5.2021., p. iv.

4 W. Kennett, The Enforcement of Judgments in Europe, Oxford University Press, Oxford 2000, p. 65.

5 Report (JLS/2004/C4/03) on the application of the Brussels I Regulation in the Member States presented by B. Hess, Th. Pfeiffer and P. Schlosser, Study JLS/C4/2005/03, Final version September 2007, Ruprecht-Karls-

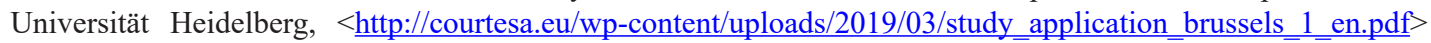
accessed 22.4.2012, referred to as the Heidelberg Report, p. 276; J. Fitchen, 'Authentic instruments and European private international law in civil and commercial matters: Is now time to break new ground?' [2011] 7 Journal of Private Internationa-l Law 33; J. Fitchen, "'Recognition", Acceptance and Enforcement of Authentic Instruments in the Succession Regulation' [2012] 8 Journal of Private International Law 323, 331. 
Para lograr una cooperación judicial transfronteriza eficaz, es necesario establecer un sistema que facilite la libre circulación de los documentos públicos y las transacciones judiciales desde el Estado miembro de origen a otros Estados miembros. Esto se estableció tempranamente, en el Convenio de Bruselas de 1968 relativo a la competencia judicial $\mathrm{y}$ a la ejecución de resoluciones judiciales en materia civil y mercantil ${ }^{6} \mathrm{y}$, posteriormente, en el Convenio de Lugano de 1988 relativo a la competencia judicial y a la ejecución de resoluciones judiciales en materia civil y mercantil. ${ }^{7}$ Algunos Estados miembros llegaron a celebrar acuerdos bilaterales para facilitar el libre flujo de instrumentos auténticos extranjeros, por ejemplo, Francia y Alemania. ${ }^{8}$ Los nuevos reglamentos de la UE, ${ }^{9}$ incluidos los Reglamento gemelos, se alejan de las nociones algo confusas empleadas en los reglamentos anteriores ${ }^{10} \mathrm{y}$ reconocen su naturaleza particular.

Al igual que la terminología innovadora empleada en las disposiciones paralelas del Reglamento de sucesiones, ${ }^{11}$ los Reglamentos gemelos parecen abrir el camino a una confianza más directa y fácil, especialmente en los documentos públicos con implicaciones transfronterizas, y por lo tanto reforzar el reconocimiento mutuo entre los Estados miembros, como un componente horizontal del principio general de confianza mutua. ${ }^{12}$

En general, los Reglamentos gemelos prevén que los efectos particulares de los documentos públicos y de las transacciones judiciales, procedentes de un Estado miembro, puedan extenderse a los demás Estados miembros. Este capítulo se centra en las nociones básicas, que incluyen los "documentos públicos", la "transacciones judiciales, la "autenticidad” y los mecanismos, que son la "aceptación” y el "otorgamiento de la ejecución". Además, comenta el número de normas procesales unificadas que son aplicables en los procedimientos relacionados con la extensión de los efectos.

Antes de entrar en detalles, es importante subrayar que los Reglamentos gemelos se aplican ratione teritorii sólo cuando el Estado miembro de origen de un documento público con fuerza ejecutiva o de una transacción judicial y el Estado miembro de ejecución ${ }^{13}$ en

6 Convenio de Bruselas relativo a la competencia judicial y a la ejecución de resoluciones judiciales en materia civil y mercantil, versión consolidada CF 498Y0126(01) [1968] DO L 299 de 31.12.1972.

7 Convenio de Lugano de 1988 relativo a la competencia judicial y a la ejecución de resoluciones judiciales en materia civil y mercantil [1988] DO L 319 de 25.11.1988, ahora sustituido por el Convenio de Lugano de 2007 relativo a la competencia judicial y al reconocimiento y ejecución de resoluciones judiciales en materia civil y mercantil [2007] DO L 339 de 21.12.2007.

8 Abkommen vom 13 September 1971 zwischen der Bundesrepublik Deutschland und der Französischen Republik über die Befreiung öffentlicher Urkunden von der Legalisation Bundesgesetzblatt BGB1. 1974 II S. 1075, $<\underline{\text { https:// }}$ www.bgbl.de> accessed 11.5.2021.

9 Véanse los artículos 59-61 del Reglamento sobre sucesiones.

10 Esto se refiere en particular a la noción de "reconocimiento" de los documentos públicos. Véase, por ejemplo, los articulos 58 a 60 del Reglamento Bruselas I bis, el articulo 46 del Reglamento Bruselas II bis (sustituido por el Reglamento Bruselas II ter desde el 1 de agosto de 2022), el articulo 48 del Reglamento sobre alimentos. Véase tambien los articulos 24 y 25 del Reglamento (CE) No 805/2004 del Parlamento Europeo y del Consejo de 21 de abril de 2004 por el que se establece un título ejecutivo europeo para créditos no impugnados [2004] DO L 143 de 30.4.2004. Anteriormente, la noción de "reconocimiento" se usaba regularmente, véase, por ejemplo, Ch. Pamboukis, L'acte public étrangere ed droit international privé, LGDJ, Paris 1993, p. 97.

11 Véanse los artículos 59-61 del Reglamento sobre sucesiones.

12 I. Kunda, 'Međunarodno privatnopravni odnosi' ['Las Relaciones del Derecho internacional privado'] in E. Mišćenić (ed.), Europsko privatno pravo: posebni dio [Derecho privado europeo: parte especial], Školska knjiga, Zagreb 2021, p. 495.

13 La expresión "Estado miembro de ejecución" se utiliza en este capítulo de forma coherente con el Reglamento sobre los gemelos, ya que implica no sólo el Estado miembro en el que el documento público con fuerza ejecutiva o 
el sentido de las letras g) y h) del apartado 1 del artículo 3 son ambos Estados miembros que participan en la cooperación reforzada establecida por los Reglamentos gemelos. Esto, por supuesto, no implica que tales instrumentos tengan que ser conocidos en la ley del Estado miembro de ejecución participante. Independientemente de si es posible o no crear un documento público con arreglo a la legislación nacional del Estado miembro de ejecución participante, dicho documento tiene que ser aceptado y/o forzado en ese Estado miembro si se crea en el Estado miembro de origen participante. ${ }^{14}$ Además, el Reglamento de Gemelos se aplica ratione temporis a los documentos públicos redactados o registrados formalmente y a las transacciones judiciales aprobadas o concluidas a partir del 29 de enero de 2019. Por último, los documentos públicos y las transacciones judiciales, para que se apliquen ratione materiae por uno u otro de los Reglamentos gemelos, deben referirse a una cuestión de bienes matrimoniales o a una cuestión de consecuencias patrimoniales de una pareja registrada, respectivamente. ${ }^{15}$ En caso contrario, quedan recogidos por otro instrumento de Derecho internacional privado de la UE o, en su defecto, por las normas de los acuerdos internacionales, si son aplicables, o por las leyes nacionales.

Además, en este punto parecen oportunas varias notas técnicas. Debido al paralelismo entre los Reglamentos gemelos, las referencias al Reglamento sobre los bienes matrimoniales en este capítulo deben entenderse también como referencias al Reglamento sobre las consecuencias patrimoniales de las parejas de hecho registradas, salvo que se indique lo contrario. En el mismo sentido, las referencias a los cónyuges o a las cuestiones patrimoniales matrimoniales deben entenderse como referencias a las parejas registradas o a las cuestiones de consecuencias patrimoniales de las parejas registradas, y similares. Además, la referencia a un "Estado miembro" se limita a los Estados miembros que participan en la cooperación reforzada establecida por los Reglamentos gemelos. ${ }^{16}$

\section{LAS NOCIONES DE "DOCUMENTO PÚBLICO" Y DE "TRANSACCIÓN JUDICIAL"}

El análisis de las nociones básicas de "documento público con fuerza ejecutiva" y "transacción judicial", su diferenciación de otras nociones como "decisión" (o "sentencia”) y el examen de sus características básicas se consideran pasos necesarios antes de abrir el debate sobre sus efectos jurídicos, que se extienden a otros Estados miembros en virtud de los mecanismos previstos en los Reglamentos gemelos.

\subsection{Definición de "documento público" con fuerza ejecutiva}

Basándose en la definición del artículo 3, apartado 1, letra i), del Reglamento sobre sucesiones, el "documento público" se define en el artículo 3, apartado 1, letra c), del Reglamento UE n 2016/1103 sobre el régimen económico matrimonial y en el artículo 3, apar-

la transacción judicial deben ser declarados ejecutorios, sino también el Estado miembro en el que los documentos públicos con fuerza ejecutiva deben ser aceptados.

14 Véase en el contexto del Reglamento Bruselas I, donde la situación era menos compleja porque todos los Estados miembros estaban implicados, Heidelberg Report, supra n. 4, p. 276.

15 Véase la letra d) del apartado 1 del artículo 3 de los Reglamentos gemelos.

16 Véanse los capítulos 2 y 3 de este volumen. 
tado 1, letra d), del Reglamento UE $n^{\circ} 2016 / 1104$ sobre los efectos patrimoniales de las uniones registradas como un documento en materia de régimen económico matrimonial/ consecuencias patrimoniales de una unión registrada que ha sido formalmente redactado o registrado como documento público en un Estado miembro y cuya autenticidad (i) se refiera a la firma y al contenido del documento público; y (ii) haya sido constatada por una autoridad pública u otra autoridad habilitada a tal efecto por el Estado miembro de origen. Mientras que el último requisito exige la participación efectiva de la autoridad pública, el primero se refiere a la capacidad cualitativa de dicha participación. Los dos requisitos son aplicables de forma acumulativa y se refieren a la calidad de un "documento público con fuerza ejecutiva" cuando se redacta o registra con arreglo a la legislación del Estado miembro de origen. Dicho esto, las disposiciones citadas no pretenden imponer ningún requisito unificado relacionado con la forma (instrumentum) ${ }^{17}$ en cuanto a los "documentos públicos" en los Estados miembros: Mientras que la competencia de los Estados miembros para regular los requisitos relacionados con la forma permanece intacta, la noción de "autenticidad" en los Reglamentos gemelos se interpreta de forma autónoma con respecto a cualquier significado nacional. ${ }^{18} \mathrm{Su}$ función es servir de criterio para ampliar los efectos de los documentos que, creados en virtud de una ley nacional de un Estado miembro, se consideran documentos públicos también en virtud de los Reglamentos gemelos.

Este esquema de doble requisito se aparta de la definición de otras legislaciones internacionales privadas de la UE que enumeran también el tercer requisito aplicable de forma acumulativa: la aplicabilidad del instrumento. Basándose en los textos de las disposiciones y en el análisis del contexto de las mismas, así como en los objetivos de los Reglamentos en cuestión y en los documentos de trabajo preparatorios, el TJUE identificó anteriormente tres requisitos que deben cumplirse para que un documento se considere auténtico. ${ }^{19}$ Procedente del Informe Jenard-Möller sobre el Convenio de Lugano, ${ }^{20}$ el esquema de los tres requisitos consiste en lo siguiente (i) la autenticidad del instrumento debe haber sido establecida por una autoridad pública, (ii) esta autenticidad debe referirse al contenido del instrumento y no sólo, por ejemplo, a la firma, y (iii) el instrumento tiene

17 Sobre estas características, véase el apartado 2.2. de este capítulo.

18 Recital 59 of the Matrimonial Property Regulation and Recital 58 of the Regulation on the Property Consequences of Registered Partnerships, which are modelled upon Recital 62 of the Succession Regulation. Although autonomous, the notion of 'authentic instruments' is built on parallel national definitions. See e.g. Article 1369 of the French Civil Code (Code civil en vigueur au 26 mai 2021 - l'article 1369 comme modifié par Ordonnance n²016-131 du 10 février 2016 dans l'article 4) which provides that an authenticated instrument (l'acte authentique) is one which has been received, with the requisite formalities, by a public official having the power and the function to draw it up. Likewise, Article 230 of the Croatian Civil Procedure Act (Zakon o parničnom postupku, Službeni list SFRJ 4/77, 36/77, 6/80, 36/80, 43/82, 69/82, 58/84, 74/87, 57/89, 20/90, 27/90 y 35/91, y Narodne novine 53/91, 91/92, 58/93, 112/99, 88/01, 117/03, 88/05, 02/07, 84/08, 96/08, 123/08, 57/11, 148/11, 25/13, 89/14 y 70/19), defines public document (which is a broader notion than the authentic instrument) as a document which is issued in the prescribed form by the state authority within the boundaries of its competence and the document which is issued in such a form by the legal or natural person in performing acts of public authority which is entrusted to her by an act or instrument based on an act. Article 3(2) of the Croatian Public Notaries Act (Zakon o javnom bilježništvu, Narodne novine, 78/93, 29/94, 162/98, 16/07, 75/09 y 120/16), provides that public notaries' documents issued pursuant to the Act have the force of public documents provided that in their composing and issuing the essential formal requirements under the Act have been fulfilled.

19 Véase, por ejemplo, el asunto C-260/97, Unibank A/S contra Flemming G. Christensen, EU:C:1999:312, párrafos $17-20$.

20 Jenard-Möller Report on the Convention on Jurisdiction and the Enforcement of Judgments in Civil and Commercial Matters done at Lugano 16 September 1988 [1990] OJ C189/57, 28.7.1990. 
que ser ejecutorio en sí mismo en el Estado miembro en el que se origina. ${ }^{21}$ Mientras que las tres son obligatorias en determinadas legislaciones pertenecientes al Derecho internacional privado de la UE, ${ }^{22}$ sólo dos son necesarias para que el instrumento jurídico sea calificado de "auténtico" en virtud del Reglamento de sucesiones ${ }^{23}$ o de los Reglamentos gemelos: ${ }^{24}$ la participación de la autoridad pública y su papel en la creación de un instrumento auténtico. Esto no supone una diferencia esencial en la definición, sino la ampliación de los tipos de efectos que deben extenderse. Al principio, los efectos de los "documentos públicos con fuerza ejecutiva" sólo podían ampliarse mediante la declaración de "fuerza ejecutiva", mientras que recientemente es posible ampliar sus efectos también mediante la "aceptación". Naturalmente, no es posible declarar ejecutorio un "documento público con fuerza ejecutiva" que, en virtud del Derecho del Estado miembro de origen, no produce tal efecto. Al fin y al cabo, no es la creación, sino la extensión de los efectos lo que implica el capítulo $\mathrm{V}$ de los Reglamentos gemelos. ${ }^{25}$

\subsubsection{Participación de la autoridad pública}

Volviendo al régimen de doble exigencia de los Reglamentos gemelos, la jurisprudencia del TJUE ofrece algunas orientaciones a pesar de que las interpretaciones se realizan dentro del régimen de triple exigencia. El requisito que exige la participación de la autoridad pública se trató en Unibank.

Unibank se refería al instituto jurídico danés del Galdsbrev, que significa reconocimiento de deuda. La cuestión central del litigio a nivel nacional y que llegó al TJUE era si un Geldsbrev podía considerarse un documento público con arreglo al Convenio de Bruselas. El TJUE recordó el informe Jenard-Möller sobre el Convenio de Lugano, que se pronunció sobre la cuestión de los documentos públicos con fuerza ejecutiva en el marco del Convenio de Lugano. ${ }^{26}$ La sentencia en el caso Unibank pasó a establecer estos requisitos como una norma en el contexto del Convenio de Bruselas. ${ }^{27}$ Como requisitos acumulativos para determinar la autenticidad de un determinado documento, llevaron al TJUE a concluir que el

21 Ibid., p. 80.

22 Véase, por ejemplo, el artículo 58 del Reglamento Bruselas I bis, el artículo 46 del Reglamento Bruselas II bis y el artículo 2, apartado 3, letra a), del Reglamento sobre alimentos. Véase también, K.H.K., que se resolvió en virtud del Reglamento (UE) $n^{\circ} 655 / 2014$, de 15 de mayo de 2014, por el que se establece un procedimiento de orden europea de retención de cuentas para facilitar el cobro transfronterizo de deudas en materia civil y mercantil [2014] DO L 189 de 27.6.2014. La cuestión planteada al TJUE consistía en determinar si un requerimiento de pago concreto en el Derecho búlgaro, el de un crédito monetario que aún no ha adquirido carácter ejecutivo, constituye un "documento público" en el sentido del artículo 4, apartado 10, del Reglamento 655/2014. El TJUE estimó que, a falta de la formulación explícita, del análisis del contexto de la disposición y del objetivo perseguido por el Reglamento 655/2014 y los trabajos preparatorios del Reglamento se desprende que, para volver a ser considerado "resolución", "transacción judicial" o "documento público" en el sentido de dicho Reglamento, un título debe ser ejecutivo en el Estado miembro de origen. En el presente caso, el requerimiento de pago aún no era ejecutivo, por lo que no constituía un documento público.

23 P. Wautelet, 'Article 3. Définitions' in A. Bonomi and P. Wautelet (eds.), Le droit européen des successions, Commentaire du règlement (UE) No 650/2012, du 4 juillet 2012, 2nd ed., Bruylant, Brussels 2016, p. 168; H.-P. Mansel, 'Article 59. Acceptance of Authentic Instruments' in A.-L. Calvo Caravaca, A. Daví and H.-P. Mansel (eds.), The European Succession Regulation, A Commentary, Cambridge University Press, Cambridge 2016, p. 637.

24 Véase, por ejemplo, el asunto C-658/17, WB c. Notario Przemysława Bac, EU:C:2019:444, párrafos 66-72.

25 Para más información, véase el apartado 3. de este capítulo.

26 Asunto C-260/97, Unibank A/S contra Flemming G. Christensen, EU:C:1999:312, párrafo 16.

27 Asunto C-260/97, Unibank A/S contra Flemming G. Christensen, EU:C:1999:312, párrafos 17-20. 
Gaeldsbrev no constituía un documento público. Esto se debió a que el Gaeldsbrev no cumplía el requisito de la participación efectiva de la autoridad pública en la autenticación del documento. Dado que el documento en cuestión fue redactado de forma privada y su autenticidad no fue "establecida por una autoridad pública u otra autoridad facultada a tal efecto por ese Estado", no constituía un documento público. $^{28}$

Dado que la intervención de la autoridad pública es un requisito previo para que un documento sea calificado como "documento público", es importante aclarar la noción de "autoridad pública u otra autoridad facultada a tal efecto por el Estado miembro de origen", tal como figura en la definición de "documento público" de los Reglamentos gemelos. Las autoridades públicas competentes para redactar un documento público son, sin duda, los tribunales y los notarios públicos, en la medida en que estén autorizados para ello en virtud de su legislación nacional, como en Croacia, donde tanto el tribunal como el notario son autoridades públicas alternativas para autenticar el tipo de acuerdo sucesorio croata: acuerdo sobre la transferencia y distribución de bienes en vida. ${ }^{29}$

En general, según la Ley del Notariado croata, el servicio notarial consiste en "la redacción y expedición oficial de documentos públicos sobre asuntos jurídicos, declaraciones y hechos en los que se basan los derechos, la certificación oficial de documentos privados, la recepción para su custodia de documentos, dinero y objetos de valor para su entrega a otras personas o autoridades, y en la realización, por orden de los tribunales u otros organismos públicos, de los procedimientos determinados por la ley", al tiempo que realiza otras tareas previstas en la propia Ley. ${ }^{30}$ Del mismo modo, el Código Federal del Notariado alemán describe a los notarios como "titulares independientes de un cargo público que son designados en los Länder para registrar actos jurídicos ("registro notarial") y realizar otras tareas en el ámbito de la administración preventiva de justicia". ${ }^{31}$ Aunque existen importantes diferencias entre las competencias de los notarios en función del Estado miembro en el que son nombrados, ${ }^{32}$ en algunos Estados miembros la competencia de los notarios es exclusiva, ${ }^{33}$ ya que son, en principio, las únicas autoridades con capacidad para crear documentos públicos. Sin embargo, como se ha indicado anteriormente, esta función no tiene por qué estar siempre reservada en exclusiva a los notarios.

28 Asunto C-260/97, Unibank A/S contra Flemming G. Christensen, EU:C:1999:312, párrafo 21.

29 Apartado 2 del artículo 106 de la Ley de sucesiones (Zakon o nasljeđivanju), Narodne novine 48/03, 163/03, 35/05, 127/13, 33/15 y 14/19. Mmás sobre el acuerdo véase I. Gliha, 'Chapter 4. Acts Inter Vivos Related to the Estate' in P. Šarčević, T. Josipović, I. Gliha, N. Hlača and I. Kunda, Family Law In Croatia, Rijnland in Leiden, Kluwer Law International 2011, pp. 280-286.

30 Artículo 2 de la Ley del Notariado croata, supra n. 17.

31 Artículo 1 del Código Federal del Notariado alemán, Bundesnotarordnung in der im Bundesgesetzblatt Teil III, Gliederungsnummer 303-1, veröffentlichten bereinigten Fassung, die zuletzt durch Artikel 5 des Gesetzes vom 4. Mai 2021 (BGB1. I S. 882) geändert worden ist.

32 En el contexto del Reglamento Bruselas I y del Reglamento sobre el título ejecutivo europeo, el TJUE demostró que la clasificación de los notarios como "órganos jurisdiccionales" en el desempeño de tareas específicas puede no ser tan clara. Véase, asunto C-551/15, Pula parking d.o.o. contra Sven Klaus Tede-rahn, EU:C:2017:193; asunto C-484/15, Ibrica Zulfikarpašić contra Slaven Gajer, EU:C:2017:199. Las sentencias del TJUE en estos casos dieron lugar a la reforma de la legislación nacional de ejecución. Véase el artículo 39 bis, apartado 4, de la Ley de Ejecución croata (Ovršni zakon, Narodne novine 112/12, 25/13, 93/14, 55/16, 73/17 y 131/20), recientemente introducido por las Enmiendas a la Ley de Ejecución (Zakon o izmjenama i dopunama Ovršnog zakona, Narodne novine 131/2020).

33 CONSEJO DE LOS NOTARIOS DE LA UNIÓN EUROPEA, supra n. 2, p. 32. 
Exclusivo o no, se considera que los notarios desempeñan una "función complementaria a la del juez". ${ }^{44}$ Sin embargo, hay que ser cauteloso, ya que también pueden actuar en otra capacidad: desempeñar una función judicial y, por lo tanto, ser considerados "órganos jurisdiccionales" en el sentido del apartado 2 del artículo 3 de los Reglamentos gemelos. Los preámbulos ofrecen una explicación: ${ }^{35}$ Cuando los notarios ejercen funciones judiciales, están vinculados por las normas de competencia establecidas en los Reglamentos gemelos, y las resoluciones que dictan circulan de conformidad con sus disposiciones relativas al reconocimiento, la ejecutoriedad y la ejecución de las resoluciones en su capítulo IV. Por el contrario, cuando los notarios no ejercen funciones judiciales no están vinculados por estas normas de competencia, sino únicamente por las del Derecho nacional (o internacional), y los documentos públicos que expiden circulan de acuerdo con las disposiciones del Reglamento sobre documentos públicos con fuerza ejecutiva, que figura en su capítulo $\mathrm{V}$.

\subsubsection{Papel de la autoridad pública}

El otro requisito del "documento público" va más allá de la mera participación de la autoridad pública y se refiere al papel de la autoridad pública in concreto. Este requisito fue tratado en particular por el TJUE en el asunto WB, ${ }^{36}$ resuelto en el marco del Reglamento sobre sucesiones. Dado que el Reglamento de sucesiones contiene la disposición que define el "documento público" que se incorpora literalmente en los Reglamentos gemelos, el primer Reglamento puede informar perfectamente la interpretación de la noción de "documento público" en el Reglamento posterior. La única diferencia entre las definiciones se refiere a los respectivos ámbitos materiales de los Reglamentos, lo que es irrelevante para la caracterización de un documento como "auténtico".

El litigio en $W B$ se refería a la definición de "documento público" frente a la "decisión" en materia de sucesión según el Reglamento de sucesiones. El instrumento en cuestión en el caso $W B$ era un instrumento nacional que certificaba la condición de heredero, concretamente el acta polaca de certificación de la sucesión redactada por un notario de acuerdo con una solicitud no contenciosa (unánime) de todas las partes del procedimiento de certificación. El TJUE diferenció entre las nociones de "documento público" y "decisión". En su sentencia, el TJUE afirma que la escritura no constituye una "decisión", ya que el notario no era el "órgano jurisdiccional" en el sentido de la disposición del artículo 3, apartado 2, del Reglamento sobre sucesiones, debido a que el notario polaco no ejerce una función judicial al otorgar la escritura nacional polaca de certificación de la sucesión tras la solicitud unánime de todas las partes interesadas. ${ }^{37}$ Por otro lado, el TJUE concluyó que dicha escritura constituye un "documento público", ya que satisface los dos requisitos del doble régimen. ${ }^{38} \mathrm{Al}$ afirmar que los notarios polacos están facultados para redactar

34 Ibid., p. 4.

35 Considerando 31 de los Reglamentos gemelos.

36 Asunto C-658/17, WB contra Notariusz Przemyslawa Bac, EU:C:2019:444.

37 Asunto C-658/17, WB contra Notariusz Przemysława Bac, EU:C:2019:444, párrafo. 61. Véase, por ejemplo. M. Wilderspin, 'The Notion of "Court" under the Succession Regulation' [2020] Problemy Prawa Prywatnego Międzynarodowego, 45-56 (acogiendo con beneplácito la decisión de aportar consistencia y coherencia teleológica al esquema del Reglamento). Véanse también los capítulos 3 y 6 de este volumen.

38 Asunto C-658/17, WB contra Notariusz Przemysława Bac, EU:C:2019:444, párrafo 71. 
los actos relativos a una sucesión y que la escritura de certificación de la sucesión se registra formalmente como un documento público, ${ }^{39}$ el TJUE se refiere a la exigencia de un documento público relativo a la intervención de la autoridad pública. En este sentido, el TJUE precisa que el acta de certificación de la sucesión nacional polaca se registra y produce, según el Derecho polaco, los mismos efectos que el auto definitivo que establece la sucesión. ${ }^{40}$ Además, el TJUE hace referencia a la exigencia de la función al afirmar que, en virtud del Derecho polaco, el notario está obligado a realizar comprobaciones de oficio, como las relativas a la competencia de los tribunales nacionales, al contenido del derecho extranjero aplicable, a la identidad del heredero, al importe de las participaciones en la herencia y, en caso de que el testador haya hecho un legado "por reivindicación", a la persona a la que el testador hizo el legado "por reivindicación" y al objeto del mismo. Dado que estas constataciones del notario conducen a su negativa a otorgar la escritura de certificación de la sucesión, la autenticidad de este instrumento se refiere tanto a su firma como a su contenido. ${ }^{41}$

\subsubsection{En papel o en formato electrónico}

Por último, en consonancia con la digitalización de todas las esferas de la vida, incluida la jurídica, es importante señalar que, si bien es inherente a la noción de documento público con fuerza ejecutiva que éste sea un documento escrito, tanto el papel como el formato electrónico, son igualmente aceptables en virtud de los Reglamentos gemelos. Esto también se aplica a las firmas que contiene, ya que pueden ser manuscritas o electrónicas. ${ }^{42}$ Algunos Estados miembros abordan explícitamente esta cuestión en sus legislaciones nacionales, como Francia. Su Código Civil establece que un documento público con fuerza ejecutiva puede ser redactado en soporte electrónico si se crea y almacena en las condiciones fijadas por decreto del Conseil d'État, ${ }^{43}$ que tienen por objeto esencialmente permitir la identificación de la persona de la que procede y garantizar la integridad del documento.

\subsection{Características del "instrumento auténtico"}

Para comprender mejor este concepto clave, los preámbulos de los Reglamentos gemelos explican y separan las características de forma (instrumentum) y de contenido (negotium) de los "documentos públicos". Por el lado de la forma, la noción de "autenticidad", siguiendo la estructura notarial latina típica de los sistemas jurídicos del Civil Law, ${ }^{44}$ abarca elementos como la autenticidad del documento, los requisitos formales del documento, los poderes de la autoridad que redacta el documento, el procedimiento de redacción

39 Asunto C-658/17, WB contra Notariusz Przemysława Bac, EU:C:2019:444, párrafo 69.

40 Asunto C-658/17, WB contra Notariusz Przemystawa Bac, EU:C:2019:444, párrafo 69.

41 Asunto C-658/17, WB contra Notariusz Przemysława Bac, EU:C:2019:444, párrafos 58 y 70.

42 P. Franzina, 'Article 58. Acceptance of Authentic Instruments' in I. Viarengo and P. Franzina (eds.), The EU Regulations on the Property Regimes of International Couples: A Commentary, Cheltenham, Edward Elgar 2020, p. 437.

43 Apartado 2 del artículo 1369 del Código Civil francés, supra n. 17.

44 En el contexto de la sucesión véase M. Weller, 'Article 3. Definitions' in A.-L. Calvo Caravaca, A. Daví and H.-P. Mansel (eds.), supra n. 22, p. 121. 
del documento y los elementos de hecho consignados en el documento público por la autoridad correspondiente. Estos últimos elementos incluyen el hecho de que las partes indicadas comparecieron ante dicha autoridad en la fecha indicada y que realizaron las declaraciones indicadas. ${ }^{45}$

\subsubsection{Elementos relacionados con la forma y el contenido}

Los elementos relacionados con la forma son principalmente de naturaleza procesal y, en consecuencia, están sujetos a la ley del Estado miembro cuya autoridad pública actúa en el contexto de la creación del documento. De conformidad con el apartado 2 del artículo 58 de los Reglamentos gemelos, la parte que desee impugnar un documento público en relación con su "autenticidad" sólo podrá hacerlo con arreglo a la ley del Estado miembro de origen. Esta norma de conflicto se ve reforzada por la norma de competencia del mismo artículo, que establece la competencia exclusiva de los tribunales del Estado miembro de origen. ${ }^{46}$

En cuanto al contenido, la noción de "actos jurídicos o relaciones jurídicas consignados en un documento público con fuerza ejecutiva" se refiere a la sustancia del documento. ${ }^{47}$ Un ejemplo es el acuerdo entre los cónyuges sobre el régimen económico matrimonial que debe aplicarse entre ellos (el acuerdo matrimonial), cuya validez formal está regulada por la regla de las normas mínimas del artículo 25, apartado 1, del Reglamento sobre el régimen económico matrimonial, mientras que el artículo 25, apartados 2 y 3 , permite la aplicación acumulativa de las normas superiores del país de la lex residentiae habitualis del cónyuge o los cónyuges en el momento de la celebración del acuerdo y de la lex causae. ${ }^{48} \mathrm{Si}$ esta ley exige la forma de un acta notarial, el documento puede calificarse de "documento público". Estos actos jurídicos y relaciones jurídicas también pueden incluir el acuerdo entre los cónyuges sobre la división de sus bienes matrimoniales, el acuerdo sobre la donación u otra declaración de intenciones que pueda afectar a los derechos relativos a los bienes matrimoniales.

Los elementos relacionados con el contenido están sujetos a la legislación aplicable según el capítulo III de los Reglamentos gemelos. ${ }^{49}$ Aunque la validez formal de un documento público se hace valer en virtud del derecho nacional de la autoridad pública emisora, la lex causae se considera aplicable a la impugnación de un "documento público" con respecto al negotium..$^{50}$ La razón de la aplicabilidad de la lex causae radica en la esencia de un litigio que tiene por objeto un régimen económico matrimonial o las consecuencias patrimoniales de una unión registrada, según el caso. La norma de conflicto del apartado 3 del artículo 58 de los Reglamentos gemelos se complementa con la de competencia que establece que la competencia para cualquier impugnación relativa a los "actos

45 El considerando 59 del Reglamento sobre los bienes matrimoniales y el considerando 58 del Reglamento sobre las consecuencias patrimoniales de las uniones registradas, que se inspiran en el considerando 62 del Reglamento sobre sucesiones.

46 Véase también P. Wautelet, 'Article 58. Acceptation des actes authentiques' in A. Bonomi and P. Wautelet (eds.), supra n. 22, pp. 1221-1222.

47 El considerando 60 del Reglamento sobre los bienes matrimoniales y el considerando 59 del Reglamento sobre las consecuencias patrimoniales de las uniones registradas, que se inspiran en el considerando 63 del Reglamento sobre las sucesiones.

48 Véase el capítulo 6 de este volumen.

49 Véase el capítulo 6 de este volumen.

50 J. Fitchen [2012], supra n. 4, 323, 327. 
jurídicos o relaciones jurídicas" consignados en un documento público corresponde a los tribunales competentes en virtud de cada uno de estos Reglamentos. ${ }^{51}$ Se trata de una referencia al complejo sistema de jurisdicción, tal y como se ha explicado anteriormente. ${ }^{52}$

También es posible que el resultado del procedimiento sobre los bienes matrimoniales o las consecuencias patrimoniales de una unión registrada dependa de la resolución de la cuestión incidental planteada, en relación con el contenido del documento público. En tal caso, el tribunal competente para decidir sobre la cuestión principal también es competente para resolver la cuestión incidental contenida en el documento público. ${ }^{53} \mathrm{Al}$ igual que en el caso de que la cuestión de contenido sea la principal del procedimiento, la ley aplicable para resolverla como cuestión incidental se determina de acuerdo con los Reglamentos gemelos, concretamente con su Capítulo III. ${ }^{54}$

\subsubsection{Distinción de las "decisiones"}

La distinción entre una "decisión" (o una "sentencia"), por un lado, y un "documento público", por otro, fue objeto de un intenso debate en los escritos académicos. El efecto de cosa juzgada se menciona como el factor crucial de delimitación. Mientras que las decisiones y sentencias derivan su fuerza ejecutiva de su carácter de cosa juzgada, los documentos públicos carecen de tal efecto. ${ }^{55}$ Esto también está relacionado con otra característica de un documento público, que a pesar de ser elaborado por una autoridad pública, posee un cierto componente privado. ${ }^{56}$ En consecuencia, su contenido es impugnable incluso después de la ejecución. Lo mismo no se aplica normalmente a las decisiones y sentencias, ya que sólo pueden ser impugnadas durante un período de tiempo limitado, ${ }^{57}$ tras el cual se convierten en definitivas y posiblemente sólo están sujetas a recursos legales extraordinarios.

\subsubsection{Distinción de los “documentos públicos” según el reglamento 2016/1191}

Es importante tener en cuenta que los diversos documentos que certifican elementos de un estado legal, como el nacimiento, el nombre, el parentesco, el matrimonio, el registro de la pareja, el estado civil, el divorcio, la disolución de la pareja, la anulación del matrimonio o de la pareja registrada, el fallecimiento, la nacionalidad, el domicilio y la residencia no están incluidos en la definición de "documento público". En cambio, sus efectos transfronterizos entre los Estados miembros se rigen por el Reglamento 2016/1191. ${ }^{58}$ El

51 Veáse al contrario en P. Beaumont, J. Fitchen and J. Holliday, The evidentiary effects of authentic acts in the Member States of the European Union, in the context of successions, European Parliament, Brussels 2016, $<$ https://www.europarl.europa.eu/RegData/etudes/STUD/2016/556935/IPOL_STU(2016)556935_EN.pdf $>$ accessed 10.5.2021, p. 34

52 Para más información, véase el capítulo 4 de este volumen.

53 Apartado 4 del artículo 58 de los Reglamentos gemelos.

54 Parece que esto también lo confirma Franzina, quien, después de discutir cuestiones procesales relacionadas con las cuestiones principales e incidentales, declara en general cuál es el derecho aplicable. P. Franzina, 'Article 58. Acceptance of Authentic Instruments' in I. Viarengo and P. Franzina (eds.), above n. 41, p. 443.

55 J. Fitchen [2011], supra n. 4, 33, 40.

56 J. Fitchen [2012], supra n. 4, 323, 327.

57 J. Fitchen [2011], supra n. 4, 33, 40 .

58 Reglamento (UE) 2016/1191 del Parlamento Europeo y del Consejo, de 6 de julio de 2016, relativo a la promoción de la libre circulación de los ciudadanos mediante la simplificación de los requisitos de presentación de determinados documentos públicos en la Unión Europea y por el que se modifica el Reglamento (UE) nº 1024/2012 [2016] DO L 200 de 26.7.2016. 
presente Reglamento se aplica a los documentos públicos expedidos por las autoridades de un Estado miembro de conformidad con su legislación nacional que deban presentarse a las autoridades de otro Estado miembro y cuyo objetivo principal sea determinar uno o varios de los hechos enumerados anteriormente. Así, simplifica los requisitos administrativos relativos a la presentación de dichos documentos públicos para garantizar su libre circulación en la UE y promover la libre circulación de los ciudadanos de la UE.

En algunas situaciones podría ser necesario delimitar cuidadosamente los "documentos públicos" en el sentido de los Reglamentos gemelos y los "documentos públicos" en el sentido del Reglamento 2016/1191. De hecho, existe un alto potencial de confusión entre ambas nociones, especialmente cuando están en juego documentos judiciales o notariales. ${ }^{59}$ Los criterios como el contenido del documento y la responsabilidad de la autoridad pública en la creación del documento podrían desempeñar un papel decisivo. Así, un documento que certifique el hecho de que existe un matrimonio entre dos personas está sujeto al Reglamento 2016/1191, mientras que un documento que contenga la declaración de uno de los cónyuges sobre la donación al otro cónyuge podría tener la calidad de "documento público" siempre que se cumplan también otros requisitos en virtud del Reglamento sobre régimen económico matrimonial. En el mismo sentido, si el notario solo autentifica las firmas de los cónyuges en el documento, este entraría en el ámbito de aplicación del Reglamento 2016/1191, mientras que la responsabilidad del notario, por ejemplo, de comprobar los contenidos de las disposiciones de los cónyuges en el documento con respecto a los requisitos legales y de informar a los cónyuges de su situación jurídica y de los efectos de sus acciones legalmente relevantes, haría que dicho documento fuera un "documento público" en virtud del Reglamento sobre regímenes económicos matrimoniales, siempre que se cumplan también otros requisitos.

Como afirma Fitchen, un documento público puede describirse en general como un "documento por el que un agente del Estado en cuestión registra formalmente y con autoridad las declaraciones realizadas por las partes para constituir dichas declaraciones como obligaciones legales". ${ }^{60}$ Dicho documento se considera de "mayor valor probatorio" que, por ejemplo, un documento con firma certificada. ${ }^{61}$ La razón de la diferenciación del "valor" radica en el necesario cumplimiento de los requisitos de forma y contenido verificados por la autoridad pública, que a su vez proporcionan al instrumento y a su titular un elevado nivel de certeza y seguridad jurídica.

\subsection{Definición de "transacción judicial"}

Al igual que en el caso de los documentos públicos con fuerza ejecutiva, la definición de "transacción judicial" que figura en el artículo 3, apartado 1, letra e), del Reglamento sobre el régimen económico matrimonial y en el artículo 3, apartado 1, letra f), del Reglamento sobre los efectos patrimoniales de las uniones registradas está tomada literalmente del Reglamento sobre sucesiones, ${ }^{62}$ que se tomó de la anterior legislación de la UE en

59 Véase la lista del artículo 3, apartado 1, del Reglamento 2016/1191.

60 J. Fitchen [2011], supra n. 4, 33.

61 CONSEJO DE LOS NOTARIOS DE LA UNIÓN EUROPEA, supra n. 2, p. 64; P. Beaumont, J. Fitchen and J. Holliday, supra n. 50, pp. 21 and 32.

62 Artículo 3(1)(h) del Reglamento de Sucesión. 
materia de Derecho internacional privado. ${ }^{63}$ Así, por "transacción judicial" se entiende "una transacción en materia de régimen económico matrimonial/efectos patrimoniales de una pareja registrada que ha sido aprobada por un tribunal, o concluida ante un tribunal en el curso de un procedimiento".

Esta noción, que está sujeta a la interpretación ${ }^{64}$ que consta de dos requisitos básicos: (i) tiene que haber un acuerdo entre las partes, y (ii) tiene que ser aprobado por un tribunal, o concluido ante un tribunal en el curso de un procedimiento ${ }^{65}$

\subsubsection{Acuerdo entre las partes}

El concepto de "acuerdos" incluiría, por ejemplo, el acuerdo de los cónyuges sobre la división de sus bienes matrimoniales, ${ }^{66} \mathrm{o}$ el acuerdo con un tercero sobre el derecho de éste que se ve afectado por el régimen económico matrimonial aplicable entre los cónyuges. Para entender el concepto de "acuerdo" es instructiva la delimitación entre una "sentencia" y un "acuerdo judicial". Esta cuestión fue objeto de deliberación en Solo Kleinmotoren. ${ }^{67}$

La cuestión preliminar que se planteó al TJUE fue si las transacciones judiciales pueden incluirse en el concepto de sentencias en virtud del apartado 3 del artículo 27 del Convenio de Bruselas, que estaba en vigor en aquel momento. El TJUE hizo una distinción estricta, afirmando que "las transacciones judiciales son esencialmente contractuales, ya que sus términos dependen en primer lugar de la intención de las partes", mientras que las sentencias deben "emanar de un órgano judicial [...] que decida por sí mismo sobre las cuestiones entre las partes". ${ }^{68}$ Aparentemente, esta última condición no se cumple en el caso de las transacciones judiciales; independientemente de que dicha transacción pueda poner fin al procedimiento judicial. El TJUE también expresó que las transacciones judiciales se rigen explícitamente por el artículo 51 del Convenio de Bruselas que contiene normas específicas para su ejecución. ${ }^{69}$

Por lo tanto, el primer requisito de la "transacción judicial" es el acuerdo entre las partes, a diferencia de la decisión de un tribunal. Sin embargo, la intervención del tribunal

63 Véase, por ejemplo, la letra e) del artículo 2 del Reglamento Bruselas I bis.

64 En el contexto del Reglamento Bruselas I bis, véase X. Kramer, in U. Magnus and P. Mankowski (eds.), Brussels Ibis Regulation: Commentary, Otto Schmidt, Köln 2016, p. 986.

65 Aunque está sujeta a una interpretación autónoma, la noción de "transacción judicial" tiene grandes similitudes con la misma noción en los sistemas jurídicos de algunos Estados miembros, como el alemán. Según el artículo 794 de la Ley de Enjuiciamiento Civil alemana (Zivilprozessordnung in der Fassung der Bekanntmachung vom 5. Dezember 2005 (BGB1. I S. 3202; 2006 I S. 431; 2007 I S. 1781), die zuletzt durch Artikel 7 des Gesetzes vom 4. Mai 2021 (BGBl. I S. 882) geändert worden), la ejecución es posible sobre la base de los acuerdos celebrados por las partes, o entre una de las partes y un tercero, para resolver el litigio en su totalidad o en lo que respecta a una parte del objeto del litigio, ante un tribunal alemán o ante una entidad de resolución de litigios establecida o reconocida por el departamento de justicia del Land (Landesjustizverwaltung), así como sobre la base de los acuerdos que se han registrado de conformidad con la tercera frase del apartado 1 del artículo 118 o el apartado 3 del artículo 492 para el registro del juez.

66 En el contexto de la sucesión, véase M. Weller, 'Article 3. Definitions' in A.-L. Calvo Caravaca, A. Daví and H.-P. Mansel (eds.), supra n. 22, p. 121.

67 Asunto C-414/92, Solo Kleinmotoren GmbH v. Emilio Boch, EU:C:1994:221.

68 Asunto C-414/92, Solo Kleinmotoren GmbH v. Emilio Boch, EU:C:1994:221, parrafos 17-18.

69 Asunto C-414/92, Solo Kleinmotoren GmbH v. Emilio Boch, EU:C:1994:221, parrafo 22. 
es necesaria, ya que el acuerdo privado entre las partes no entra en el ámbito de las "transacciones judiciales". Esto nos lleva al segundo requisito.

\subsubsection{Implicación del tribunal}

La intervención del tribunal puede adoptar cualquiera de las dos formas siguientes (i) el acuerdo de las partes se alcanza fuera del tribunal y el procedimiento judicial se ha iniciado con el fin de aprobar formalmente el acuerdo ex post, o (ii) el tribunal se ocupa del procedimiento en el que el asunto termina por un acuerdo de las partes celebrado en este procedimiento ante el tribunal. En el primer caso, los tribunales pueden, en virtud de las leyes de algunos Estados miembros, certificar las declaraciones de las partes realizadas en los acuerdos. Esto funciona como una excepción de la competencia excluyente de los notarios para autentificar las declaraciones de las partes, como se ha explicado anteriormente. ${ }^{70}$ Sin embargo, los tribunales sólo pueden producir documentos públicos en algunos Estados miembros y en asuntos específicos. En Alemania, el artículo 127 a) del Código Civil alemán, titulado "Transacción judicial", establece que, en caso de transacción judicial, el registro de declaraciones en un acta judicial redactada de conformidad con las disposiciones del Código de Procedimiento Civil (Zivilprozessordnung) sustituye al registro notarial. ${ }^{71}$ Cuando el tribunal actúa aprobando el acuerdo, es necesario que la participación del tribunal consista en la revisión activa del acuerdo. ${ }^{72}$ Por analogía con la noción de "documento público", ${ }^{73}$ dicha actividad debe estar relacionada tanto con la firma como con el contenido.

\subsubsection{Distinción de las “consent judgments" (sentencias basadas en acuerdo de las partes)}

Puede plantearse la cuestión de si el efecto de res iudicata (cosa juzgada) de la transacción judicial puede descalificarla de la definición del artículo 3, apartado 1, letra e), del Reglamento sobre regímenes económicos matrimoniales y del artículo 3, apartado 1, letra f), del Reglamento sobre los efectos patrimoniales de las uniones registradas, porque dicho efecto es la esencia de la decisión. No hay una respuesta directa a esta cuestión en la definición de la "transacción judicial". Además, en ninguna parte de los Reglamentos gemelos se menciona el efecto de la res iudicata ni para incluirlo ni para excluirlo de la definición de la noción de "transacción judicial". Esto crea dificultades en la interpretación, ya que los sistemas jurídicos de los distintos Estados miembros atribuyen efectos diversos a los acuerdos de las partes celebrados con la participación de los tribunales.

En el informe de Heidelberg relativo al Reglamento de Bruselas I, las "consent judgments", como se denominan allí según este concepto en el Derecho inglés, no se consideran transacciones judiciales en el sentido del artículo 58 del Reglamento, sino que deben calificarse como resoluciones judiciales que se reconocen en virtud del artículo

70 CONSEJO DE LOS NOTARIOS DE LA UNIÓN EUROPEA, supra n. 2, p. 32.; P. Beaumont, J. Fitchen and J. Holliday, supra n. 50, p. 19.

71 Bürgerliches Gesetzbuch in der Fassung der Bekanntmachung vom 2. Januar 2002 (BGBl. I S. 42, 2909; 2003 I S.738), das zuletzt durch Artikel 1 des Gesetzes vom 9. Juni 2021 (BGBl. I S. 1666) geändert worden ist).

72 X. Kramer, in U. Magnus and P. Mankowski (eds.), supra n. 63, p. 987.

73 La autoridad pública tiene que autentificar el instrumento tanto en lo que respecta a la firma como al contenido. Véase el subcapítulo 2.1 anterior. 
32 del mismo. ${ }^{74}$ Por analogía, el mismo efecto de res iudicata calificaría las "consent judgments" en materia matrimonial y en materia de consecuencias patrimoniales de las uniones registradas como "decisiones" en el sentido del artículo 3, apartado 1, letra d), del Reglamento sobre el régimen matrimonial y del artículo 3, apartado 1, letra e), del Reglamento sobre efectos patrimoniales de las uniones registradas, y no como "court settlements".

La falta de efecto de res iudicata como razón mencionada para tal conclusión parece convincente si se tiene en cuenta el hecho de que el sistema de reconocimiento y ejecución de resoluciones del Reglamento Bruselas I, y su sucesor -el Reglamento Bruselas I bis-, enumera la irreconciliabilidad con otra resolución entre los motivos de denegación del reconocimiento y la ejecución, ${ }^{75}$ mientras que las disposiciones sobre transacciones judiciales permiten la denegación de la declaración de su ejecutoriedad sin otro motivo que la violación manifiesta del orden público del Estado miembro de ejecución. ${ }^{76}$ Por lo tanto, la ausencia de res iudicata como motivo de denegación de la declaración de ejecutoriedad de las transacciones judiciales podría considerarse como una indicación de que la noción de "transacción judicial" no incluye ningún acto jurídico o documento que tenga efecto de res iudicata. De lo contrario, el sistema adolecería de una grave incoherencia: la irreconciliabilidad sería un obstáculo para las sentencias que no se basan en el acuerdo de las partes, pero no lo sería si las partes han acordado el resultado del procedimiento y lo han hecho constar en la "sentencia de consentimiento". De hecho, esta interpretación refuerza la creación del espacio judicial único en materia civil (en la UE o en una parte de ella que participe en la cooperación reforzada) en el que se internan los sistemas de reconocimiento y ejecución para descartar la posibilidad de que los derechos y obligaciones de las partes que son definitivos y ejecutables en un Estado miembro entren en conflicto con dichos derechos y obligaciones en otro Estado miembro.

Suponiendo que la interpretación anterior sea correcta, ninguna transacción judicial, tal y como se entiende en las leyes nacionales croatas o eslovenas, podría calificarse como transacción judicial en el sentido del artículo 3, apartado 1, letra e), del Reglamento sobre régimen económico matrimonial y del artículo 3, apartado 1, letra f), del Reglamento sobre los efectos patrimoniales de las uniones registradas. En el sistema jurídico croata, la transacción judicial, de conformidad con la legislación procesal nacional, significa el acuerdo de las partes que se hace en forma de acta del proceso judicial, firmado por las partes, por lo que se convierte en definitivo, final ejecutorio, según sea el caso. ${ }^{77}$ Debido a que no se puede llevar a cabo ningún otro procedimiento en el asunto que previamente terminó con la transacción judicial en el sentido de la ley nacional croata, se ha concluido que la objeción procesal de rei iudicaliter transactae equivale a la objeción procesal de

74 Heidelberg Report, supra n. 4, pp. 66 and 277.

75 Artículo 45, apartado 1, y articulo 46 del Reglamento Bruselas I y del Reglamento Bruselas I bis. Véanse también los artículos 37 y 47 del Reglamento sobre el régimen económico matrimonial y el Reglamento sobre las consecuencias patrimoniales de las uniones registradas.

76 Artículo 59 en relación con el apartado 1 del artículo 58 del Reglamento de Bruselas I y del Reglamento de Bruselas I bis. Véase también el apartado 3 del artículo 60 del Reglamento sobre el régimen económico matrimonial y el Reglamento sobre las consecuencias patrimoniales de las uniones registradas.

77 Véanse los artículos 321-324 de la Ley de Procedimiento Civil de Croacia (Zakon o parničnom postupku), Službeni list SFRJ 4/77, 36/77, 6/80, 36/80, 43/82, 69/82, 58/84, 74/87, 57/89, 20/90, 27/90 y 35/91, y Narodne novine 53/91, 91/92, 58/93, 112/99, 88/01, 117/03, 88/05, 02/07, 84/08, 96/08, 123/08, 57/11, 148/11, 25/13, 89/14 y $70 / 19$. 
rei iudicatae en la ley croata. ${ }^{78}$ Del mismo modo, la legislación eslovena establece que el tribunal tiene que rechazar de oficio la acción siempre que haya una resolución judicial previa en el asunto pendiente ante él, lo que encarna el principio ne bis in idem. ${ }^{79}$ Por lo tanto, la transacción judicial según el derecho nacional esloveno es la res trans-acta, que tiene el mismo efecto que la res iudicata y se aplica lo mismo a la transacción judicial que a la sentencia definitiva. ${ }^{80}$ Por consiguiente, lo que los sistemas jurídicos croata y esloveno consideran "transacción judicial" dictada por el tribunal del país respectivo se caracterizaría como "sentencia" o "decisión", en lugar de "transacción judicial" a efectos del reconocimiento y/o la ejecución en virtud de los reglamentos de la UE en materia de Derecho internacional privado. Dicho esto, el poder judicial cuyo derecho nacional no conoce las "transacciones judiciales" en el sentido de los Reglamentos gemelos, sigue teniendo la obligación de aplicar los Reglamentos para ejecutar las "transacciones judiciales" procedentes de otros Estados miembros.

\subsection{Ampliación de los efectos de los documentos públicos con fuerza ejecutiva y de las transacciones judiciales}

La libre circulación de los ciudadanos de la UE se ve reforzada por su capacidad de confiar directamente en un único documento legal en varios Estados miembros. En consecuencia, el Derecho internacional privado de la UE muestra una tendencia a relajar los procedimientos formales relacionados con el uso del documento en todos los Estados miembros distintos del Estado miembro de origen. Cuanto más relajados sean los requisitos para extender los efectos de los actos y documentos jurídicos públicos, mayor será la confianza mutua necesaria entre los Estados miembros. ${ }^{81}$ Siguiendo los pasos de los demás Reglamentos de la UE en el ámbito del derecho internacional privado, los Reglamentos gemelos suprimen todos los requisitos de legalización u otra formalidad similar respecto a los documentos expedidos en un Estado miembro en el contexto del respectivo Reglamento. ${ }^{82}$ Los Reglamentos gemelos garantizan además la "aceptación" y la declaración de "fuerza ejecutiva" en todos los Estados miembros participantes de los documentos públicos con fuerza ejecutiva en materia de patrimonio matrimonial y en materia de consecuencias patrimoniales de las uniones registradas, respectivamente. También garantizan la declaración simplificada de "fuerza ejecutiva" de las transacciones judiciales.

78 L. Vojković, 'Pravna priroda sudske nagodbe' ['Naturaleza jurídica del transacción judicial'], 40 Zbornik Pravnog fakulteta Sveučilišta u Rijeci [Colección de ensayos de la Facultad de Derecho de la Universidad de Rijeka] (2019), p. 957, 964.

79 Artículo 308 de la Ley de Enjuiciamiento Civil (Zakon o pravdnem postopku), Uradni list RS, 73/07 - uradno prečiščeno besedilo, 45/08 - ZArbit, 45/08, 111/08 - odl. US, 57/09 - odl. US, 12/10 - odl. US, 50/10 - odl. US, 107/10 - odl. US, 75/12 - odl. US, 40/13 - odl. US, 92/13 - odl. US, 10/14 - odl. US, 48/15 - odl. US, 6/17 - odl. US, 10/17, 16/19 - ZNP-1 in 70/19 - odl. US).

80 Tribunal Supremo de la República de Eslovenia, II Ips 877/2009, 17.05.2012, SI:VSRS:2012:II.IPS.877.2009; N. Betetto and A. Galič in L. Ude and A. Galič (eds.), Pravdni postopek: Zakon s komentarjem, 3. Knjiga [Proceso Civil: Acto con Comentario, Tercer Libro], Uradni list/GV Založba, Ljubljana 2009, p. 45.

81 I. Kunda, 'Međunarodnoprivatnopravni odnosi' ['Las Relaciones de Derecho Internacional Privado'] in E. Mišćenić (ed.), supra n. 11, pp. 498-500.

82 Artículo 61 de los Reglamentos gemelos. La supresión de estos requisitos también se contempla en el Convenio de La Haya de 5 de octubre de 1961 por el que se suprime la exigencia de legalización de los documentos públicos extranjeros, que introdujo en su lugar la apostilla. 
La "aceptación" y la "ejecutoriedad" se refieren a los efectos de los documentos públicos y las transacciones judiciales. La fuerza probatoria y ejecutiva de un documento público $^{83}$ se deriva de los poderes de la autoridad pública que interviene en su creación y del procedimiento formal pertinente prescrito por la legislación nacional del Estado miembro de origen. Mientras que la fuerza probatoria se refiere al potencial probatorio que se otorga al documento en el Estado miembro de origen, la fuerza ejecutiva en el Estado miembro de origen hace que el documento sea ejecutable sin necesidad de iniciar ningún procedimiento judicial o administrativo adicional. ${ }^{84}$ Asimismo, los efectos ejecutivos de la transacción judicial se derivan de la participación de los tribunales en la conclusión o aprobación del acuerdo de las partes sobre la materia en un litigio pendiente, e igualmente a los documentos públicos con fuerza ejecutiva como tales. Sin embargo, para que estos efectos se extiendan fuera del Estado miembro de origen debe existir un mecanismo de Derecho internacional privado. Los Reglamentos gemelos distinguen dos mecanismos de este tipo: la "aceptación" de los documentos públicos con fuerza ejecutiva y la "declaración de ejecutoriedad" de los documentos públicos con fuerza ejecutiva y las transacciones judiciales.

\section{5. “Aceptación” de los documentos públicos con fuerza ejecutiva}

\subsubsection{La noción de "aceptación"}

La noción de "aceptación" se introdujo por primera vez en la legislación internacional privada de la UE en virtud del Reglamento sobre sucesiones. ${ }^{85}$ Haciéndose eco de la anterior redacción del TJUE, ${ }^{86}$ presenta el "hito" en la construcción del sistema de libre circulación de documentos públicos. ${ }^{87}$ Se reprodujo en los Reglamentos gemelos continuando la tendencia a la extensión simplificada pero restringida de los efectos jurídicos que se derivan de los auténticos instrumentos entre los Estados miembros.

Esta terminología innovadora sólo figura en el título del artículo 58 de los Reglamentos gemelos, sin repetirse en el texto de las propias disposiciones. A falta de una definición del concepto de "aceptación" en los Reglamentos gemelos, la redacción de las disposiciones contenidas en ellos es la más relevante para entender su significado. La primera frase del apartado 1 del artículo 58 establece que Un documento público con fuerza ejecutiva formalizado en un Estado miembro surtirá en otro Estado miembro los mismos efectos probatorios que en el Estado miembro de origen, o los más comparables, siempre que ello no sea manifiestamente contrario al orden público del Estado miembro de que se trate". Por lo tanto, la "aceptación" está directamente relacionada con los "efectos probatorios" (o la fuerza probatoria, como a veces se denomina) de un documento público. Como tal, la "aceptación" se refiere precisamente al instrumentum, no al negotium. ${ }^{88}$

83 J. Fitchen [2012], supra n. 4, 323, 327.

84 P. Wautelet, 'Article 58. Acceptation des actes authentiques' in A. Bonomi and P. Wautelet (eds.), supra n. 22, p. 1218.

85 Artículo 58 del Reglamento sobre sucesiones.

86 Véase el asunto C-336/94, Eftalia Dafeki, EU:C:1997:579, pararafo 19.

87 P. Wautelet, 'Article 58. Acceptation des actes authentiques' in A. Bonomi and P. Wautelet (eds.), supra n. 22, p. 1213.

88 P. Franzina, 'Article 58. Acceptance of authentic instruments' in I. Viarengo and P. Franzina (eds.), supra n. 41, pp. $438-439$. 
Esta interpretación es coherente con los trabajos preparatorios (traveaux preparatoire) en el curso de la adopción de la disposición paralela en el Reglamento sobre sucesiones, sobre la que se modelaron finalmente las de los Reglamentos gemelos. La historia legislativa vuelve a revelar que el concepto de "reconocimiento" de los documentos públicos con fuerza ejecutiva recibió duras críticas, desde una perspectiva esencialmente doctrinal, por el desorden que crea en las estructuras del Derecho internacional privado. ${ }^{89}$ Se ha manifestado una preocupación acuciante por el hecho de que el uso de la noción de "reconocimiento" pueda implicar el reconocimiento del estatuto jurídico sin el recurso clásico a las normas de conflicto de leyes. ${ }^{90} \mathrm{El}$ nuevo enfoque pretende así diferenciar el concepto de "aceptación" del concepto de "reconocimiento". ${ }^{91}$ Básicamente, su objetivo es reducir la extensión de los efectos de los documentos públicos en otros Estados miembros. ${ }^{92}$ Apoyándose ambos en el principio de reconocimiento mutuo como política subyacente, los dos mecanismos de extensión de los efectos jurídicos entre los Estados miembros funcionan de forma diferente. El documento público no puede tener los mismos efectos extendidos en virtud del capítulo $\mathrm{V}$ de los Reglamentos gemelos que la decisión cuando se "reconoce" en virtud del capítulo IV de los Reglamentos gemelos. Por lo tanto, la nueva terminología debe asegurar no sólo la diferenciación formal entre los mecanismos de "aceptación" y "reconocimiento" y los documentos a los que se dirigen, sino también la funcional, que se manifiesta en la diferente naturaleza de los efectos que se extienden apoyándose en cada uno de los mecanismos.

\subsubsection{Extensión de los efectos probatorios}

Tal como se describe en el considerando 58 del Reglamento sobre regímenes económicos matrimoniales y en el considerando 57 del Reglamento sobre los efectos patrimoniales de las uniones registradas, el documento público con fuerza ejecutiva debe aceptarse con los mismos efectos probatorios que en el Estado miembro de origen o, en su defecto, con los efectos más comparables. A la hora de determinar los efectos probatorios de un determinado documento público en otro Estado miembro o los efectos más comparables, debe hacerse referencia a la naturaleza y el alcance de los efectos probatorios del documento público en el Estado miembro de origen. Los efectos probatorios que un determinado documento público debe producir en otro Estado miembro dependerán, por tanto, de la legislación del Estado miembro de origen. La referencia clara a esta ley no facilita la tarea de los tribunales del Estado miembro de ejecución, dadas las variaciones de los efectos jurídicos producidos por los documentos públicos en los distintos Estados miembros. ${ }^{93}$

89 Véase H.-P. Mansel, 'Article 59. Acceptance of Authentic Instruments' in A.-L. Calvo Caravaca, A. Daví and H.-P. Mansel (eds.), above n. 22, pp. 634-635, y abundantes referencias en el mismo.

90 W.H. Rechberger, 'Cross-Border Enforcement of Public Documents' in V. Rijavec, K. Drnovšek and C.H. van Rhee (eds.), Cross-Border Enforcement in Europe: National and International Perspectives, Cambridge, Intersentia 2020, p. 77.

91 É. Fongaro, 'Les successions' in H. Péroz and É. Fongaro, Droit international privé patrimonial de la famille, 2nd ed., Paris, LexisNexis 2017, p. 321.

92 R. Geimer, ‘,Annahme“ ausländischer öffentlicher Urkunden in Erbsachen gemäß Art. 59 EuErbVO', in A. Dutta and S. Herrler (eds.), Die Europäische Erbrechtsverordnung, München, C.H. Beck 2014, pp. 143-160.

93 Aunque no se trate de documentos públicos, sino de documentos públicos que certifican la fecha de nacimiento, las circunstancias del caso Eftalia Dafeki demuestran lo mucho que puede variar el valor probatorio de los documentos entre los Estados miembros. Véase el asunto C-336/94, Eftalia Dafeki, EU:C:1997:579, para. 12. 
La amplitud de estas variaciones fue precisamente el motivo que llevó a los legisladores de la UE a incluir una disposición específica para la aceptación de los "efectos más comparables" como opción alternativa cuando no sea posible la aceptación de los efectos exactos determinados por el Estado miembro de origen. ${ }^{94}$ La imposibilidad mencionada no es, lógicamente, tan grave como para provocar la aplicación de la cláusula de orden público. ${ }^{95}$ Sin embargo, es lo suficientemente grave como para constituir una perturbación de las estructuras jurídicas procesales del Estado miembro de ejecución como para que la técnica de adaptación ${ }^{96}$ sea solicitada por la autoridad del Estado miembro de ejecución que está presente con el documento público en cuestión. Como dice acertadamente Franzina, los efectos más comparables son los que son "funcionalmente equivalentes (en la mayor medida posible) a los efectos derivados del instrumento en virtud de la legislación del Estado [miembro] de origen". ${ }^{97}$ Para ello es necesario comprender la naturaleza y el alcance de los efectos probatorios de un documento público en el Estado miembro de origen en comparación con los efectos internos. De hecho, el Derecho internacional privado de la UE está exigiendo a los tribunales y otras autoridades que desarrollen progresivamente sus competencias en materia de metodología de Derecho comparado.

\subsubsection{Formulario normalizado opcional}

Cuando una persona desee invocar un documento público con fuerza ejecutiva en un Estado miembro distinto del Estado miembro de origen, podrá solicitar el formulario normalizado ${ }^{98}$ que figura en el anexo II del Reglamento de ejecución, ${ }^{99}$ que será expedido por la autoridad que haya creado el documento en cuestión. Además de indicar la información esencial sobre el documento público en cuestión, como el Estado miembro de origen, la fecha del documento, los nombres de las partes, el formulario permite a la autoridad pública detallar los efectos jurídicos derivados del documento, incluidas las declaraciones de las partes consignadas en él, los hechos verificados por la autoridad pública, si puede servir de base para la inscripción del derecho en el registro de bienes muebles o inmuebles y si fue impugnado.

94 P. Wautelet, 'Article 58. Acceptation des actes authentiques' in A. Bonomi and P. Wautelet (eds.), supra n. 22, p. 1219. In the context of the Succession Regulations see J. Fitchen [2012], supra n. 4, 323, 356-357; H.-P. Mansel, 'Article 59. Acceptance of Authentic Instruments' in A.-L. Calvo Caravaca, A. Daví and H.-P. Mansel (eds.), supra n. 22, pp. 652-653. For the opposing opinion see U. Simon and M. Buschbaum, 'Die neue EUErbrechtsverordnung Aufsatz' [2012] 62 Neue Juristische Wochenschrift 2393, 2397.

95 Sobre la cláusula de orden público, véase el apartado 3.1.5. de este capítulo.

96 Esta técnica se emplea en el artículo 29 del Reglamento sobre los derechos reales. Véase el capítulo 5 de este volumen.

97 P. Franzina, 'Article 58. Acceptance of authentic instruments' in I. Viarengo and P. Franzina (eds.), supra n. 41, p. 440.

$98 \mathrm{La}$ forma debe establecerse de acuerdo con el procedimiento consultivo a que se refiere el art. 67.2, que señala además el art. 4 del Reglamento (UE) no 182/2011 del Parlamento Europeo y del Consejo, de 16 de febrero de 2011, por el que se establecen las normas y los principios generales relativos a las modalidades de control por los Estados miembros del ejercicio de las competencias de ejecución por la Comisión [2011] DO L 55 de 28.2.2011.

99 Reglamento de Ejecución (UE) 2018/1935 de la Comisión, de 7 de diciembre de 2018, por el que se establecen los formularios contemplados en el Reglamento (UE) 2016/1103 del Consejo por el que se establece una cooperación reforzada en el ámbito de la competencia, la ley aplicable y el reconocimiento y la ejecución de las resoluciones en materia de regímenes económico matrimoniales, C/2018/8145 [2018] DO L 314, 11.12. 2018; Reglamento de Ejecución (UE) 2018/1990 de la Comisión, de 11 de diciembre de 2018, por el que se establecen los formularios contemplados en el Reglamento (UE) 2016/1104 del Consejo por el que se establece una cooperación reforzada en el ámbito de la competencia, la ley aplicable y el reconocimiento y la ejecución de las resoluciones en materia de régimen económico matrimonial, C/2018/8226 [2018] DO L 320 de 17.12.2018. 
Resulta interesante que los Reglamentos gemelos utilicen la palabra "puede solicitar" cuando se refiere al uso del documento público en un Estado miembro distinto del de origen. Esto implica que el formulario no es obligatorio y que el documento público puede ser invocado en ese Estado miembro incluso por sus propios méritos (junto con la traducción jurada, según el caso). Independientemente del hecho de que el formulario no sea obligatorio, puede considerarse como un medio ventajoso para comunicar a la autoridad del Estado miembro distinto del de origen la información esencial sobre el documento público, en particular, la inscripción de los efectos probatorios. ${ }^{100}$ Esto puede ser muy útil, especialmente en situaciones en las que hay que aplicar la técnica de adaptación para permitir la extensión de los efectos más comparables en el Estado miembro de aplicación.

\subsubsection{Retos y obstáculos para la "aceptación”}

Hay varias razones diferentes por las que no se aceptará un documento público extranjero. Las ya mencionadas impugnaciones de la autenticidad del documento y las impugnaciones del fondo de los actos jurídicos o de las relaciones jurídicas registradas impiden la aceptación si la impugnación ha prosperado. Esto lo decidirá la autoridad competente del Estado miembro de origen (la cuestión de la autenticidad) o el tribunal competente en virtud de los Reglamentos gemelos (el fondo). Mientras la impugnación esté pendiente ante la autoridad competente, el documento público con fuerza ejecutiva en cuestión no podrá producir ningún efecto probatorio en ninguno de los demás Estados miembros en relación con el aspecto que se impugna. ${ }^{101} \mathrm{Si}$ el instrumento acaba siendo declarado nulo y su aceptación rechazada, ya no puede producir efectos probatorios.

\subsubsection{El orden público como motive de denegación de la "aceptación"}

Sin embargo, la aceptación sólo puede denegarse por un único motivo de revisión: si es manifiestamente contraria al orden público del Estado miembro de ejecución. Este motivo de denegación de la aceptación se establece en el primer apartado relativo a los documentos públicos. Según la jurisprudencia reiterada del TJUE, el orden público comprende los principios fundamentales de un Estado miembro y de su ordenamiento jurídico (incluidos los principios internacionales y europeos en ese Estado miembro), pero las fronteras exteriores a estos principios están definidas por el ordenamiento jurídico de la UE con el fin de restringir el alcance del orden público al sentido estricto pertinente para los casos con elemento internacional. ${ }^{102}$ Por lo tanto, para considerar que un acto es "contrario al orden público" y, en consecuencia, rechazar su aceptación, no basta con la mera discrepancia entre los dos ordenamientos jurídicos, sino que es necesario que el documento público sea totalmente repugnante desde el punto de vista de los principios fundamentales del Estado miembro de ejecución. Además, la contrariedad del documento público en cuestión con el orden público del Estado miembro de ejecución debe ser "manifiesta". Este requisito significa que la violación debe ser clara y evidente, por lo que no cabe impugnar un do-

100 P. Beaumont, J. Fitchen and J. Holliday, supra n. 50, p. 43.

101 Apartados 2 y 3 del artículo 58 de los Reglamentos gemelos.

102 Véase el asunto C-7/98 Krombach, EU:C:2000:164, para. 22-23; el asunto C-38/98 Renault, EU:C:2000:225, parrafo 27-28; Case C-302/13, flyLAL-Lithuanian Airlines, EU:C:2014:2319, parrafo 47. Veáse más in I. Kunda, 'Međunarodnoprivatnopravni odnosi' ['Las Relaciones de Derecho Internacional Privado'] in E. Mišćenić (ed.), supra n. 11, pp. 546-548. 
cumento público basándose en este motivo en cualquier caso. ${ }^{103}$ Por ejemplo, la cláusula de orden público puede activarse en situaciones en las que la emisión de un documento público en cuestión estuviera vinculada a un delito, como la corrupción, el fraude o la coacción. Sin embargo, es probable que estos motivos se consideren también razones para impugnar el documento público con arreglo a la legislación del Estado miembro de origen y hacer que se declare inválido, lo que redundaría en beneficio de alguna de las partes del mismo o de un tercero. De ser así, no podrían derivarse efectos probatorios de dicho documento inválido en ninguno de los Estados miembros de posible ejecución. ${ }^{104}$ Sin embargo, si, a pesar de estas graves infracciones, el instrumento no es invalidado en el Estado miembro de origen, la cláusula de orden público podría demostrar su utilidad. ${ }^{105}$

\subsubsection{Incompatibilidad con otros documentos públicos, acuerdos o decisiones judiciales}

Aunque no se menciona explícitamente en el Capítulo V de los Reglamentos gemelos, la situación en la que el tribunal de otra autoridad del Estado miembro de ejecución recibe un documento público con fuerza ejecutiva, una transacción judicial o una resolución incompatible con el documento público con fuerza ejecutiva se aborda parcialmente en el preámbulo, aunque de forma algo ambigua. ${ }^{106}$ En la jurisprudencia del TJUE se establece que la irreconciliabilidad existe cuando las decisiones "conllevan consecuencias jurídicas que se excluyen mutuamente". ${ }^{107}$

El conflicto entre instrumentos auténticos múltiples e incompatibles puede referirse a los respectivos efectos probatorios inherentes a los instrumentos (instrumentum) o al acto jurídico o la relación jurídica contenida en los instrumentos (negotium). Lo primero no es frecuente, mientras que lo segundo puede ocurrir cuando las partes modifican posteriormente sus disposiciones anteriores. ${ }^{108}$ De conformidad con el considerando 63 del Reglamento sobre los bienes matrimoniales y el considerando 62 del Reglamento sobre las consecuencias patrimoniales de las uniones registradas, el conflicto de prioridad entre documentos públicos incompatibles debe ser resuelto por la autoridad a la que se presenten en el Estado miembro de ejecución, teniendo en cuenta las circunstancias en cada caso. Si de estas circunstancias no se desprende con claridad a qué documento público, en su caso, debe darse prioridad, la cuestión debe ser resuelta por los tribunales competentes en virtud de los Reglamentos gemelos o, cuando la cuestión se plantee como cuestión incidental en el curso de un procedimiento, por el tribunal que conozca de dicho procedimiento.

En caso de incompatibilidad entre un documento público con fuerza ejecutiva y una decisión, el mismo considerando establece que deben tenerse en cuenta los mo-

103 Para más información sobre políticas públicas, véase el capítulo 6 de este volumen.

104 Véase el considerando 62 del Reglamento sobre los bienes matrimoniales y el considerando 61 del Reglamento sobre las consecuencias patrimoniales de una unión registrada.

105 La utilidad de la cláusula ha sido cuestionada en P. Wautelet, 'Article 58. Acceptation des actes authentiques' in A. Bonomi and P. Wautelet (eds.), supra n. 22, pp. 1228-1229.

106 Para este relato en relación con el considerando paralelo del Reglamento sobre la sucesión, véase H.-P. Mansel, 'Article 59. Acceptance of Authentic Instruments' in A.-L. Calvo Caravaca, A. Daví and H.-P. Mansel (eds.), supra n. 22, p. 662.

107 Asunto C-145/86 Hoffman v Krieg, EU:C:1988:61, parrafo 22 .

108 P. Wautelet, 'Article 58. Acceptation des actes authentiques' in A. Bonomi and P. Wautelet (eds.), above n. 22, p. 1232. 
tivos de no reconocimiento de las decisiones en virtud del pertinente del Reglamento gemelo. Esto debe entenderse como una referencia a las normas de prioridad entre las resoluciones irreconciliables en virtud del artículo 37 de los Reglamentos gemelos. Si el conflicto es entre un documento público con fuerza ejecutiva extranjero procedente de un Estado miembro participante y una decisión nacional, esta última debería tener prioridad de acuerdo con el apartado (c). ${ }^{109} \mathrm{Si}$ el conflicto se produce entre un documento público extranjero procedente de un Estado miembro participante y una resolución anterior dictada en otro Estado miembro participante, en un Estado miembro no participante o en un tercer Estado, esta última también debe prevalecer con arreglo a la letra d), siempre que la resolución anterior cumpla las condiciones necesarias para su reconocimiento en el Estado miembro de ejecución (en realidad, reconocimiento). Estas disposiciones no abordan la incompatibilidad entre los documentos públicos con fuerza ejecutiva nacionales y las resoluciones extranjeras de cualquier país, lo que puede interpretarse como que los documentos públicos con fuerza ejecutiva nacionales gozan de prioridad a menos que la autoridad del Estado miembro participante en cuestión decida lo contrario, lo que quedaría a su entera discreción en lo que respecta a los Reglamentos gemelos.

Los Reglamentos gemelos no dicen nada sobre el conflicto entre los documentos públicos y las transacciones judiciales. Teniendo en cuenta la naturaleza de las transacciones judiciales, el conflicto podría resolverse bajo los mismos principios que el conflicto de incompatibilidad entre dos documentos públicos.

\section{6. "Declaración de ejecutividad" de los documentos públicos con fuerza ejecutiva y de las transacciones judiciales}

Las disposiciones de los artículos 59 y 60 de los Reglamentos gemelos establecen las normas aplicables al "otorgamiento de la ejecución" (exequátur) de los documentos públicos y las transacciones judiciales, respectivamente. Para que un documento público con fuerza ejecutiva o una transacción judicial originados en un Estado miembro participante y con fuerza ejecutiva en ese Estado sean ejecutados en otro Estado miembro participante, deben ser declarados como tales de acuerdo con el procedimiento mencionado anteriormente en los Reglamentos gemelos en el contexto del reconocimiento y la declaración de fuerza ejecutiva de las resoluciones. Dado que los artículos 59 y 60 son idénticos, sus disposiciones se examinan conjuntamente.

\subsubsection{Ejecución en el Estado miembro de origen}

Un documento público con fuerza ejecutiva o una transacción judicial a los que se refieren los artículos 59 y 60 de los Reglamentos gemelos tienen que llevar en sí mismos la cualidad de ejecutables con arreglo a la legislación del Estado miembro del que proceden. Según Wautelet, el acto tiene que ser ejecutivo ex lege y por su propia naturaleza. ${ }^{110}$ Así pues, frente a los efectos probatorios que se refieren al mecanismo de aceptación de los documentos públicos, lo que está en juego es el efecto de ejecutoriedad. En varios Esta-

109 Se ha afirmado que dicho resultado sería en todo caso lógico y automático. Ibid., p. 1233.

110 P. Wautelet, 'Article 59. Force exécutoire des actes authentiques' in A. Bonomi and P. Wautelet (eds.), supra n. 22, p. 1236 ; P. Wautelet, 'Article 60. Force exécutoire des transactions judiciaires' in A. Bonomi and P. Wautelet (eds.), supra n. 22, p. 1251. 
dos miembros, especialmente en los que reconocen los documentos notariales, los documentos públicos poseen esta cualidad, que debe determinarse con arreglo a la legislación del Estado miembro de origen. También las liquidaciones judiciales deben producir el efecto ejecutivo que se recoge en el artículo 60 de los Reglamentos gemelos, efecto que se deriva del derecho del Estado miembro de origen.

La calidad de ejecutorio se acredita en el formulario normalizado emitido por el tribunal o la autoridad competente del Estado miembro de origen. ${ }^{111}$ Se pretende, entre otras cosas, detallar si la totalidad o sólo algunas obligaciones del documento público con fuerza ejecutiva o de la transacción judicial tienen la cualidad de ejecutables.

\subsubsection{Procedimiento de declaración de la fuerza ejecutiva en el Estado miembro de ejecución}

El procedimiento se rige por las normas contenidas en los artículos 44-57 de los Reglamentos gemelos aplicadas mutatis mutandis al otorgamiento de la ejecución de un documento público o de una transacción judicial. El procedimiento de solicitud se rige generalmente por la ley del Estado miembro de ejecución; ${ }^{112}$ sin embargo, algunas cuestiones están total o parcialmente reguladas por las normas de procedimiento unificadas de los Reglamentos gemelos, que sólo se abordan brevemente aquí, ya que se han desarrollado anteriormente. ${ }^{113}$

El procedimiento de otorgamiento de la ejecución comienza con la presentación de la "solicitud" por parte de un "interesado", de conformidad con el artículo 59, apartado 1, de los Reglamentos gemelos. El concepto de "parte interesada" incluye no sólo a las partes del documento público con fuerza ejecutiva o de la transacción judicial, sino también a cualquier otra persona que se vea afectada por el régimen de propiedad pertinente y pueda tener un interés jurídico en la ejecución del documento público con fuerza ejecutiva o de la transacción judicial en cuestión. ${ }^{114}$ Pueden ser los cónyuges o las parejas registradas o terceros cuyos derechos dependen del régimen económico matrimonial o del régimen patrimonial de la pareja registrada o de las disposiciones realizadas por los cónyuges o las parejas registradas. Por ejemplo, el acreedor de una de las partes que tenga un interés directo en el acto jurídico o en la relación jurídica contenida en el documento público o en la transacción judicial puede presentar una solicitud de declaración de ejecución. ${ }^{115}$ El apartado 2 del artículo 45 de los Reglamentos gemelos impide la aplicación de un requisito común en las leyes procesales nacionales de los Estados miembros para que la parte contra la que se incoa el procedimiento tenga una dirección postal o un representante autorizado en el Estado miembro de ejecución. En su lugar, algunas normas unificadas sobre la notificación de documentos deberían facilitar la comunicación transfronteriza entre el tribunal o la autoridad competente y el solicitante. ${ }^{116}$

111 Apartado 2 del artículo 60 en relación con la letra b) del apartado 3 del artículo 45 de los Reglamentos gemelos.

112 Apartado 1 del artículo 45 de los Reglamentos gemelos.

113 Véase el capítulo 6 de este volumen.

114 P. Franzina, 'Article 59. Enforceability of authentic instruments' in I. Viarengo and P. Franzina (eds.), supra n. 41, p. 449.

115 P. Wautelet, ‘Article 60. Force exécutoire des transactions judiciaires' in A. Bonomi and P. Wautelet (eds.), supra n. 22, p. 1253.

116 Véase el Reglamento (CE) n ${ }^{\circ}$ 1393/2007 del Parlamento Europeo y del Consejo, de 13 de noviembre de 2007, relativo a la notificación y al traslado en los Estados miembros de documentos judiciales y extrajudiciales en materia civil o mercantil (notificación y traslado de documentos) y por el que se deroga el Reglamento (CE) $\mathrm{n}^{\circ}$ 
La "solicitud" presentada ante el tribunal o la autoridad competente del Estado miembro de ejecución debe ir acompañada de (a) una copia del documento público con fuerza ejecutiva o de la transacción judicial en cuestión, que cumpla las condiciones necesarias para establecer su autenticidad, y (b) el certificado emitido por el tribunal o la autoridad competente del Estado miembro de origen utilizando el formulario normalizado. ${ }^{117}$ Dicho formulario figura en el Anexo II del Reglamento de aplicación. Si el mencionado certificado no se presenta junto con la solicitud, el tribunal o la autoridad competente tiene tres opciones: puede fijar un plazo para su presentación, aceptar un documento equivalente o renunciar a él por completo. Esto último se hará si el tribunal o la autoridad competente considera que ya tiene suficiente información para decidir sobre la solicitud de exequátur. ${ }^{118}$ La traducción o transliteración del documento público con fuerza ejecutiva o de la transacción judicial en cuestión no es obligatoria en virtud de los Reglamentos gemelos, pero el tribunal o la autoridad competente que se ocupa de la solicitud de ejecución puede pedirla al solicitante. Es importante tener en cuenta que, aunque la traducción solicitada tiene que ser una traducción oficial, es decir, hecha por una persona cualificada para hacer traducciones, ${ }^{119}$ esta persona no tiene por qué ser del Estado miembro de ejecución. Es igualmente aceptable que la traducción sea realizada por una persona cualificada en cualquier Estado miembro. En términos prácticos, esto es una manifestación más del principio de reconocimiento mutuo.

La persona interesada puede presentar la solicitud de otorgamiento de la ejecución ante el tribunal o la autoridad competente del Estado miembro de ejecución que sea competente de conformidad con el artículo 64 de los Reglamentos gemelos. Según esta disposición, los Estados miembros debían comunicar a la Comisión la información sobre sus tribunales competentes a tal efecto. La lista de tribunales competentes puede encontrarse en línea, en el Atlas Judicial Europeo en Materia Civil, concretamente en su portal de justicia electrónica. ${ }^{120}$ No obstante, de conformidad con el artículo 44(2) de los Reglamentos gemelos, la competencia local se determina por referencia al domicilio de la parte contra la que se solicita la ejecución, o al lugar de ejecución. Para determinar si, a efectos del procedimiento de otorgamiento de la ejecución, una parte está domiciliada en el Estado miembro de ejecución, el órgano jurisdiccional que conozca del asunto aplicará el Derecho interno de dicho Estado miembro. ${ }^{121}$ Al igual que en el Reglamento Bruselas I bis ${ }^{122}$ y otros instrumentos de Derecho internacional privado de la UE, no existe una definición autónoma del domicilio de una persona física. A diferencia del Reglamento Bruselas I, los Reglamentos gemelos sólo contienen una norma de conflicto unilateral que apunta a la aplicación de una sola ley: la lex fori. Esto es probablemente el resultado del contexto en el que operan las disposiciones. Cuando se establece la competencia para

1348/2000 del Consejo [2007] DO L 324 de 10.12. 2007, que será sustituido a partir del 1 de julio de 2022 por el Reglamento (UE) 2020/1784 del Parlamento Europeo y del Consejo, de 25 de noviembre de 2020, relativo a la notificación y al traslado en los Estados miembros de documentos judiciales y extrajudiciales en materia civil o mercantil (notificación y traslado de documentos) (refundición) [2020] DO L 405 de 2.12.2020.

117 Apartado 3 del artículo 45 de los Reglamentos gemelos.

118 Apartado 1 del artículo 46 de los Reglamentos gemelos.

119 Apartado 2 del artículo 46 de los Reglamentos gemelos.

120 Véase el Atlas Judicial Europeo en Materia Civil, Portal de e-Justicia, <https://e-justice.europa.eu $>$ in particular $<$ https://e-justice.europa.eu/559/EN/matters_of_matrimonial_property regimes?CROATIA\&member=1 $>$ consultado el 27.4.2021.

121 Artículo 43 de los Reglamentos gemelos.

122 Véase el artículo 62 del Reglamento Bruselas I bis. 
el otorgamiento de la ejecución en los Reglamentos gemelos, no es necesario determinar el domicilio en ningún otro Estado miembro que no sea el Estado miembro de ejecución. Sin embargo, lo mismo puede ser necesario cuando se determina la competencia sobre el fondo del litigio en virtud del Reglamento de Bruselas I, en particular en lo que respecta al ámbito de aplicación personal de muchas de sus disposiciones sobre competencia, que depende de que el demandado esté domiciliado en un Estado miembro. ${ }^{123}$

El documento público con fuerza ejecutiva o la transacción judicial de que se trate se declarará ejecutiva inmediatamente después del cumplimiento de las formalidades previstas en el artículo 45 del Reglamento ${ }^{124}$ Del mismo modo que un solicitante puede pedir un otorgamiento de ejecución limitado a partes de un documento público con fuerza ejecutiva o de una transacción judicial, el tribunal o la autoridad competente puede declarar la ejecución parcial sólo respecto de uno o varios elementos del documento público con fuerza ejecutiva o de la transacción judicial. ${ }^{125}$ En el presente procedimiento no se permite la revisión del documento público con fuerza ejecutiva ni de la transacción judicial, por lo demás aplicable a las decisiones en virtud del artículo 37 de los Reglamentos gemelos. Además, el tribunal o la autoridad competente que lleve a cabo el procedimiento de otorgamiento de la ejecución no podrá modificar el subestado del documento público o de la transacción judicial, ni en su totalidad ni en parte. ${ }^{126}$ Así pues, no puede negarse a declarar la ejecutoriedad del documento público con fuerza ejecutiva o de la transacción judicial en cuestión si se cumplen los requisitos formales y no se manifiesta ninguna violación del orden público. La parte contra la que se solicita la ejecución no está facultada, en esta fase del procedimiento, para presentar alegaciones a la demanda. ${ }^{127}$ Pueden solicitarse medidas provisionales y cautelares sobre la base del documento público con fuerza ejecutiva o de la transacción judicial en cuestión, de conformidad con el artículo 53 de los Reglamentos gemelos, para proteger los intereses de una parte en particular, a la espera de la decisión sobre la ejecutoriedad y/o la decisión sobre el recurso que impugna la declaración de ejecutoriedad.

\subsubsection{Recursos legales contra el auto de ejecución}

De conformidad con los artículos 49 ó 50 de los Reglamentos gemelos, la decisión sobre la solicitud de otorgamiento de la ejecución puede ser recurrida por cualquiera de las partes ante el tribunal del Estado miembro de ejecución comunicado a la Comisión de conformidad con el artículo 64 de los Reglamentos gemelos. ${ }^{128}$ Según lo dispuesto en el apartado 5 del artículo 49 de los Reglamentos gemelos, el recurso sólo puede interponerse en un plazo de 30 o 60 días a partir de su notificación, según el domicilio del destinatario. El plazo más largo de 60 días, calculado a partir de la fecha de notificación, ya sea a la parte contra la que se solicita la ejecución en persona o en su residencia, se aplica a las situaciones en las que dicha parte está domiciliada en un Estado miembro distinto de

123 Véanse, por ejemplo, los artículos 4 y 7 del Reglamento Bruselas I bis.

124 Artículo 47 de los Reglamentos gemelos.

125 Artículo 54 de los Reglamentos gemelos.

126 P. Wautelet, 'Article 60. Force exécutoire des transactions judiciaires' in A. Bonomi and P. Wautelet (eds.), supra n. 22, p. 1254.

127 Article 47 of the Twin Regulations.

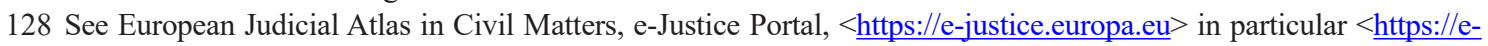
justice.europa.eu/559/EN/matters of matrimonial_property_regimes?CROATIA\&member=1 $>$ accessed 27.4.2021. 
aquel en el que se dictó el otorgamiento de la ejecución. En todas las demás situaciones, se aplica el plazo más corto de 30 días.

Con el fin de garantizar el respeto del principio de autdiatur et altera pars, el procedimiento del recurso debe llevarse a cabo de acuerdo con las normas que rigen el procedimiento en materia contradictoria. Además, el tribunal tiene que actuar de acuerdo con el artículo 16 de los Reglamentos gemelos si la parte contra la que se solicita la ejecución no comparece ante el tribunal de apelación en un procedimiento relativo a un recurso interpuesto por el solicitante, independientemente del lugar en el que esté domiciliada dicha parte. El artículo 50 de los Reglamentos gemelos prevé un recurso ulterior contra la decisión en el procedimiento de apelación y se refiere estrictamente al procedimiento comunicado por el Estado miembro de ejecución a la Comisión de conformidad con el artículo $64 .{ }^{129}$ En ese caso, el tribunal ante el que se presenta el recurso sólo revocará la declaración de ejecutoriedad si la ejecución del documento público o la transacción judicial fuera manifiestamente contraria al orden público del Estado miembro de ejecución. Esto se recoge en el art. 59(3) de los Reglamentos gemelos y hace referencia al concepto ya debatido en el contexto de la aceptación de los documentos públicos y el reconocimiento, la fuerza ejecutiva y la ejecución de las resoluciones. ${ }^{130}$

Si se emite la declaración de ejecutoriedad y el plazo para interponer un recurso ha expirado sin que se haya presentado ningún recurso o si el recurso ha sido rechazado, la ejecución puede comenzar, de acuerdo con la legislación del Estado miembro de ejecución.

\section{OBSERVACIONES FINALES}

El enfoque de la regulación de la circulación de los documentos públicos y de la transacción judicial adoptado en los Reglamentos gemelos no supone cambios radicales si se compara con los sistemas paralelos establecidos en otros reglamentos de Derecho internacional privado de la UE. Al seguir la misma estructura y replicar las disposiciones respectivas del Reglamento de sucesiones, los Reglamentos gemelos pertenecen, sin embargo, al grupo de Reglamentos con terminología modernizada y concepción de los mecanismos de extensión de los efectos de los documentos públicos y las transacciones judiciales entre los Estados miembros.

Hasta ahora, estos tipos de actos, a saber, los documentos públicos y las transacciones judiciales, sólo han representado una parte menor del número total de actos que circulan entre los Estados miembros. Tal vez con el aumento de la autonomía de las partes para elegir la ley aplicable a un asunto matrimonial o a una cuestión de consecuencias patrimoniales de la unión registrada, ${ }^{131}$ la confianza de los cónyuges y las parejas registradas en su autonomía para regular los aspectos sustantivos de sus relaciones patrimoniales también aumentará en consecuencia. Por lo tanto, cabe esperar que la importancia de estos actos, especialmente en las situaciones transfronterizas, aumente, poniendo a prueba las disposiciones respectivas más que ocasionalmente.

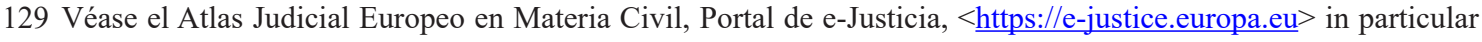
$<$ https://e-justice.europa.eu/559/EN/matters_of matrimonial property regimes?CROATIA\&member=1> consultado el 27.4.2021.

130 Véase el apartado 3.1.5. de este capítulo y el apartado 6 de este volumen.

131 Véase el capítulo 5 de este volumen. 